\title{
MACHINE LEARNING APPLIED TO ICFES TESTS TO IDENTIFY MEASUREMENT PATTERNS IN STUDENTS
}

\author{
DANIEL MARTÍNEZ ${ }^{1}$, OCTAVIO JOSÉ SALCEDO PARRA ${ }^{2} \&$ MARCO ANTONIO AGUILERA \\ PRADO $^{3}$ \\ 1,2 Faculty of Engineering, Universidad Distrital Francisco José de Caldas, Bogotá, Colombia \\ ${ }^{3}$ Vice-presidency for Research. Universitaria Agustiniana. Bogotá, Colombia
}

\begin{abstract}
In this paper, we will analyze the different techniques of Machine Learning in higher education through the information stored in the Colombian Institute for the Evaluation of Education in Colombia (Icfes) to measure the most relevant characteristics for a student to get both positive and negative results. For this, we will use algorithms based on the Regression Model, known as supervised algorithms: Nä̈ve Bayes and $K$ Nearest Neighbors, whose functions are to determine through the distance between two points, which can be related and the selection of variables, taking into account the class variable and its dependencies on the data.

The standardized tests were created in 2009, and since then, they have collected on average more than one million data, detailed enough to know general aspects such as family, origin, school, assets, among others, and specific ones (qualifications). Combining the information from recent years will make it possible for us to analyze the progress on education and what extent of the most deficient variables should be improved to help students become holistic human beings.
\end{abstract}

KEYWORDS: Machine Learning, Regression Model, K-Nearest neighbour, Nä̈ve Bayes \& Algorithms

Received: Nov 07, 2020; Accepted: Nov 27, 2020; Published: Dec 03, 2020; Paper Id.: IJMPERDDEC20201

\section{INTRODUCTION}

In the last few years, it is not strange to read news about technological advances that have a direct impact on the society, here the multiple computer systems have a place, the internet, robots, among many other tools that are created with the initial philosophy of empowering and helping in the development of society. So, beyond the innovation, it's worth asking yourself how these tools they begin to interact with people; well, in the last who have a direct interaction with the machines and in a world in which there is greater access to technology, results important to know how it interacts with society. Within the large group of technologies that exist the subject of Artificial intelligence (AI) is particular, because if you goes back to famous films such as I Robot (2004), Terminator (1984), A.I. Artificial Intelligence (2001), among others; the situation that a machine, robot or similar has own thought makes a reaction develop (fear in some), due to their capacity, reach and intentions that they can develop.

Recently there was a debate between the founder of Tesla: Elon Musk and the founder of Facebook: Mark Zuckerberg. The first mentioned that should start be proactive against the implementation of technologies such as AI, before it's too late to react to unfavorable events as a result of poor development of the technology. For its part, the founder of Facebook, rejected strongly Musk's statements arguing that He was being incendiary and that some type is not necessary of regulation. 
About who is the reason it is quite difficult to take a decision, however, although there are websites like The Atlantic [1] that say that the reactions are more focused to the interests of each of the companies that they handle; the certain thing is that it is possible to pose a scenario in which the technology as AI, which can also be extended to autonomous vehicles, home automation, personal assistants, among others; will make part of the daily life of people and considering a regulation of this type of technology is fully rational.

\section{RESEARCH METHOD}

\subsection{Research Activities}

The execution of the algorithms to monitor the entire measurement process of the found patterns is carried out through the following characteristics:

- Obtain the Data from the icfes FTP Server through the following URL ftp://ftp.icfes.gov.co/

- Request access to the FTP Server by filling in the data through the following URL https://www.icfes.gov.co/formulario-ftp and wait within a period of possibly 5 work days to obtain the credentials.

- Once the above is fulfilled, we proceed to enter the link of the FTP server to find all the pertinent information to the Icfes data (In this case, Know pro)

The variables to use are the following:

Table 1: Icfes variables

\begin{tabular}{|l|l|}
\hline \multicolumn{1}{|c|}{ Mathematics } & \multicolumn{1}{|c|}{$\begin{array}{c}\text { Critical } \\
\text { reading }\end{array}$} \\
\hline Written communication & Specific tests \\
\hline Performance & college \\
\hline Academic program & Residing area \\
\hline Internet dedication & $\begin{array}{l}\text { Daily Reading } \\
\text { Dedication }\end{array}$ \\
\hline $\begin{array}{l}\text { Goods (Video games, TV, PC, } \\
\text { washing machine, car, motorcycle) }\end{array}$ & Bilingual school \\
\hline Family education (Father and Mother) & Gender \\
\hline Stratum & Department \\
\hline
\end{tabular}

Along with the above, the average range of information

Table 2: Description of basic information Saber Pro average semester

\begin{tabular}{|l|l|}
\hline \multicolumn{1}{|c|}{ RangeIndex } & \multicolumn{1}{|c|}{\begin{tabular}{c}
\multicolumn{1}{|c|}{ 260756 entries, } \\
0 to 260755
\end{tabular}} \\
\hline Columns & $\begin{array}{l}106 \\
\text { ESTU_TIPODOCUMENTO entries, } \\
\text { Unnamed: } 105\end{array}$ \\
\hline dtypes & to \\
\hline Memory usage & $210.9+\mathrm{MB}$ \\
\hline
\end{tabular}

The document has a total of 105 attributes, each one with numerical and categorical data; according to this, each attribute is validated and the data balancing is carried out.

The attributes on the test scores (math, English, reading, comprehension, global and specific scores), have a stable balance, which can be compared to a Gauss bell, however, there are attributes regarding basic information on students that 
have been distributed in an unbalanced way, as occurs with the stratum, department, and institution, among others.

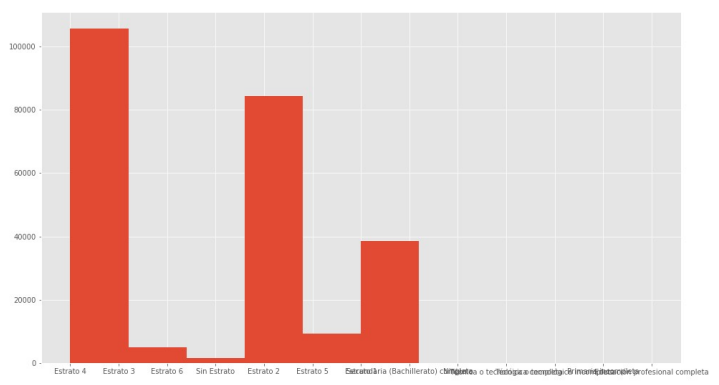

Figure 1: Information stratum 2019. Source: Authors

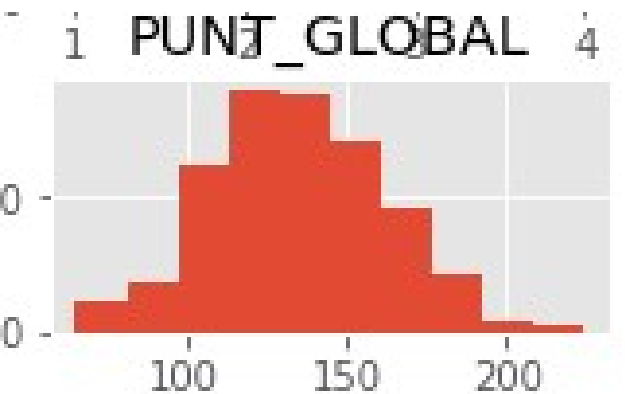

Figure 2: Overall exam score. Source: Authors

Taking one of the attributes as an example gives the following: [10 rows $\mathrm{x} 106$ columns]

Table 3: Anomalous data verification example

\begin{tabular}{|l|l|}
\hline \multicolumn{2}{|c|}{ FAMI_ESTRATOVIVIENDA } \\
\hline 0 & 16367 \\
\hline Complete professional education & 1 \\
\hline Stratum 1 & 38547 \\
\hline Stratum 2 & 84240 \\
\hline Stratum 3 & 80127 \\
\hline Stratum 4 & 25379 \\
\hline Stratum 5 & 9400 \\
\hline Stratum 6 & 5031 \\
\hline None & 1 \\
\hline Incomplete primary & 1 \\
\hline Complete Secondary (Baccalaureate) & 3 \\
\hline Without Stratum & 1656 \\
\hline Complete technical or technological & 2 \\
\hline Incomplete technical or technological & 1 \\
\hline dtype: int64 & \\
\hline
\end{tabular}

The anomalous data is located in each column because there is a displacement of records in other columns, however, the amount is minimal, given that when you compare the total amount of data $(260,756)$ versus the anomalous quantity it does not exceed $1 \%$, so they are eliminated. Once the data is analyzed, the Machine Learning algorithms are used:

- Use of the Python programming language through the open source multiplatform integrated development environment called Spyder.

- Spyder has advanced editing, interactive tests, debugging, introspection, and a numerical computing environment, along with popular Python libraries such as NumPy, SciPy, or matplotlib (2D / 3D interactive plotting). 
- Spyder is obtained through Anaconda, which is a free and open distribution of the Python and R languages, used in data science, and machine learning, including processing of large volumes of information, predictive analysis and scientific computations, and is aimed at simplifying the deployment and administration of software packages.

- Anaconda has the majority of libraries installed for their respective use in data analysis.

- The Saber Pro exam is made up of two parts: generic questions and specific questions, depending on the career, both parts or one must be presented, in this case the selection was based on general tests such as mathematics, reading and communication, due to which are basic factors before the specific test, however, tests related to generic ones such as: engineering, teaching and economics were integrated.

\subsection{Algorithms}

The data stored in the Icfes Database have an indicator capable of connecting variables between different files (student with results and data on their Saber 11, Saber Pro tests), which allows verifying the evolution that the student has had throughout the time; what changes is the year of the ID, which is removed and the unique number is registered and related to their other information.

\section{3. $\quad K$ - Nearest Neighbors}

The algorithm is based on the neighboring classification of data until it obtains a set of optimal information that can determine the amount of data that are related to each other. To calculate the distances, the following algorithm is used:

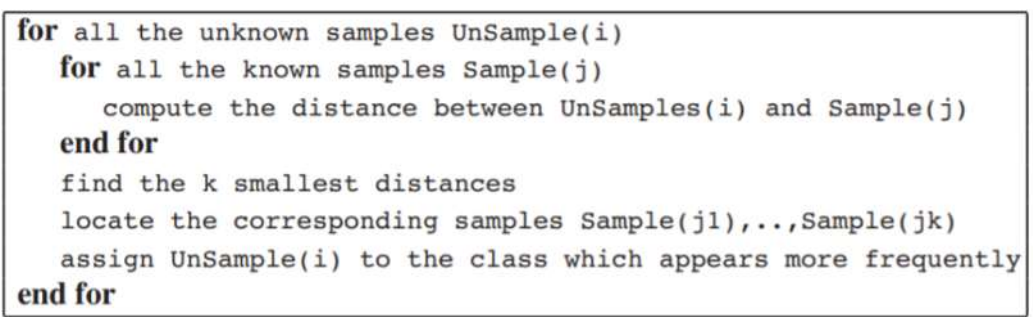

Figure 3. Algorithm K Nearest Neighbors. Source: [6]

Which the summation of components is carried out through two training sets in absolute value:

$$
|x|\left|\sum_{i=1}^{k}\right| x_{i} \mid \text { (1) }
$$

The following refers to the square root of the sum of the squares of the components of Vector X:

$$
|x| \mid \sqrt{\sum_{i=1}^{n}\left(x_{1}\right)^{2}}
$$

By applying the K Nearest Neighbors algorithm

$$
\begin{aligned}
& n \_n e i g b o r s=15 \\
& k n n=\text { KNeighborsClassifier(n_neighbors) }
\end{aligned}
$$

The KNeighborsClassifier Function has: 
- Calculated distance with the Euclidean function to calculate the distance between the points.

- A uniform weight, that is, all the points in each neighborhood that weigh the same

- Selection of 15 neighbors for the information registered in the tables along with the qualifications, because they are the most important to carry out the Machine Learning process:

knn.fit (X_train, $y_{-}$train.values)

The "fit" function adjusts the variables that are related to apply the prediction, both of the training and test data and thus verify its effectiveness.

\subsubsection{Naive Bayes}

It is an algorithm that helps describe the relationship of conditional probabilities of statistical quantities based on Bayesian rules, with the assumption of attributes that are conditionally independent of the class, offering high precision in the classification algorithms, since being a supervised algorithm allows a process of a simple extraction, classification (training and testing) and precision, each one with the estimation of the independent variable with the dependent $P(X \mid Y)$, in which each class is $\mathrm{Y}$ given the objects $\mathrm{X}$, and once obtained, the classification is carried out: [7] [8].

$$
P\left(x_{i} \mid y\right)=\frac{1}{\sqrt{2 \pi \sigma_{y}^{2}}} \exp \left(-\frac{\left(x_{i}-\mu_{y}\right)^{2}}{2 \sigma_{y}^{2}}\right)
$$

The Naive Bayes application, through the Gaussian Model, takes $X_{i}$ as the amount of data, $Y$ the class, the parameters $\sigma_{y}$ and $\mu_{y}$ (mean of the variable $X$ ) estimated with the maximum likelihood, and the normal distribution [9].

The development of the algorithm in the tests Saber Pro applies the formula through the function gnb = GaussianNB(), that takes the data and the class $(X \mid Y)$, which contains the maximum likelihood and classification of the data.

However, as the number of columns is 105 , the best characteristics are chosen best $=\operatorname{SelectKBest}(k=14)$; In this case, $60 \%$ of the variables are taken, so that the characteristics that are selected can classify the data in a uniform way:

$$
\begin{aligned}
& X_{-} \text {new }=\text { best.fit_transform }(X, y . \text { values }) \\
& \text { selected }=\text { best.get_support }(\text { indices }=\text { True })
\end{aligned}
$$

Likewise, the $\mathrm{k}$ best variables stored in the best variable they are fitted and transformed by means of fit_transform (), in order to be able to use get_support() and verify the degree of correlation until reaching the training, test and precision process by means of $f i t(\operatorname{train}[$ features] $) \rightarrow$ test.

\section{RESULTS AND DISCUSSIONS}

Selection of variables that stand out from the student's information and the scores obtained. 


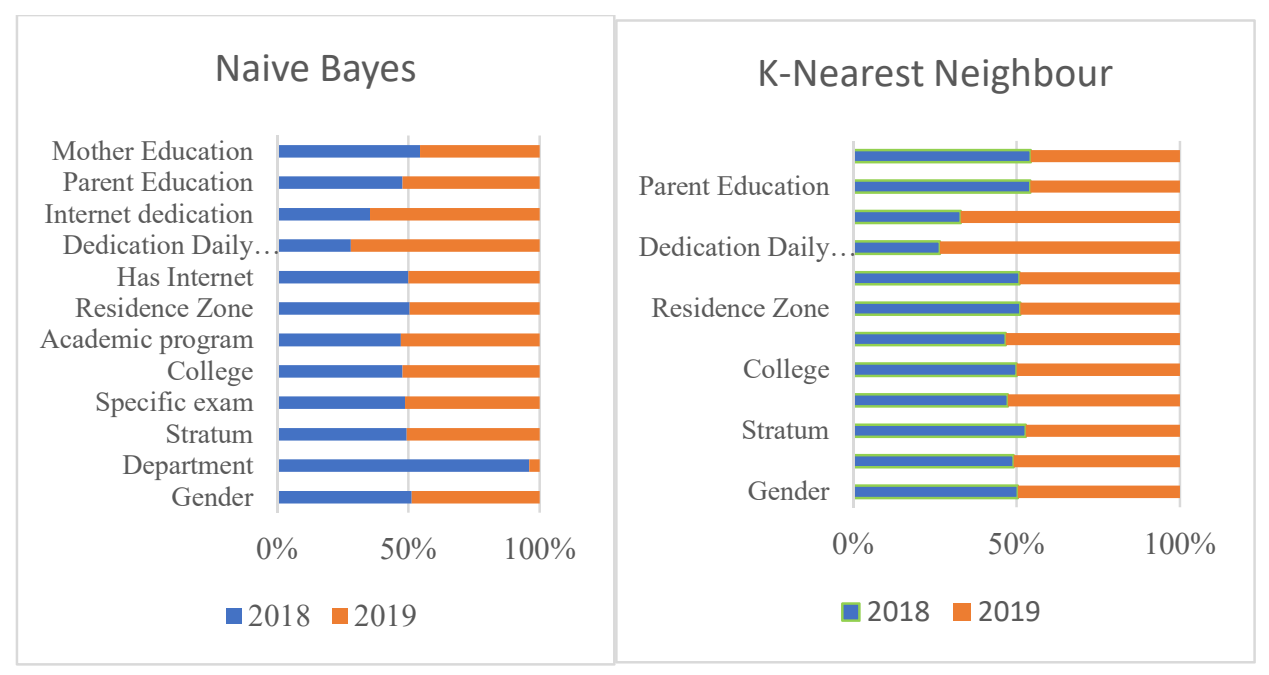

Figure 4: Results with Naive Bayes. Source: Authors

Figure 5. Results with K Nearest Neighbors. Source:

Authors

\subsection{Naive Bayes}

In the Figure 4, it shows how in Colombia the number of people who want to obtain a university degree has gradually increased, and how the decision is affected by variables such as:

- The support of parents, education, information technology, gender, residential areas and stratum, due to the fact that they exceed the immediately previous results by an average of $10 \%$.

- The lack of the necessary tools for the training process in rural areas affects the positive results of students, where the percentage remained stable during these three years.

- The accessibility of information continues to be maintained in large cities, as advances are increasing, along with the time they dedicate to learning and those related to daily reading and the use of the internet.

When making the comparison with the article by Cameron C. Gray and Dave Perkins, where they identified the behavior of students at Bangor University (Great Britain) for 3 weeks, to establish the result of the students with Naive Bayes algorithms, trees, random forest and decision tables, a precision of $97 \%$ is established, however, a factor to be highlighted is that the lowest percentage in error is the Naive Bayes algorithm with $0.31 \%$, which allows to promote the use of these technologies and the model as part of a more complete support mechanism for the student, together with an adequate pedagogy according to the results obtained. [10]

\subsubsection{K Nearest Neighbors}

Figure 5 shows that the data increases over time and is above the mean, where the following results are identified:

- The mother has a stake in the home equal to that of the father.

- Internet use and reading increased by more than $50 \%$ in the last year

- The urban area continues to be the preferred site for applying for higher education, as there are no significant changes in the results obtained.

- The motivation to carry out learning processes increased by $10 \%$ compared to the previous year. 
- The support of the family nucleus continues to be relevant in the formation of children.

In the research obtained on the performance of the students in the PISA tests through Machine Learning [11] the following is visualized:

The selection of variables used were math scores, gender, work time, use of tools such as internet, video games, sports, reading and education and parental support, where it is highlighted that in the results in the math test, France, Japan and Germany, have a higher percentage than the average (53\%), due to the economic and emotional support of the parents and together with the above, the importance of the other variables is broken down: work time, sports, reading, internet, among others, that is, they are directly proportional to achieve good grades in quality tests of Education.[11].

\subsection{Best Forecasting Model}

According to the quantitative results to determine patterns in the students with the Icfes database in 2018 and 2019, applying the supervised algorithms, the following average was obtained:

Table 4: Average result algorithms

\begin{tabular}{|l|l|l|}
\hline & \multicolumn{1}{|c|}{$\begin{array}{c}\text { K-Nearest } \\
\text { Neighbors }\end{array}$} & Naive Bayes \\
\hline Gender & $65 \%$ & $62 \%$ \\
\hline Department & $28 \%$ & $13 \%$ \\
\hline Stratum & $46 \%$ & $38 \%$ \\
\hline Specific exam & $19 \%$ & $20 \%$ \\
\hline College & $16 \%$ & $12 \%$ \\
\hline Academic program & $8 \%$ & $45 \%$ \\
\hline $\begin{array}{l}\text { Results Mathematics, reading and } \\
\text { written communication }\end{array}$ & $65 \%$ & $61 \%$ \\
\hline Residence Zone & $85 \%$ & $86 \%$ \\
\hline It has internet & $87 \%$ & $83 \%$ \\
\hline Dedication Daily Reading & $68 \%$ & $70 \%$ \\
\hline Internet dedication & $75 \%$ & $78 \%$ \\
\hline Parent education & $36 \%$ & $23 \%$ \\
\hline Mother education & $35 \%$ & $22 \%$ \\
\hline
\end{tabular}

According to the results obtained in the data measurement through Machine Learning algorithms to identify patterns on the Saber Pro tests, it was possible to determine:

- Assets and the economy, the stratum and the residential area are the parameters that stand out the most in Colombia according to the information on each student $(60 \%)$.

- The higher percentages presented by the general variables of the student, such as family education, dedication to study, motivation and stratum, among others, influence the increase in test scores, being directly proportional to obtaining good results.

- Among the algorithms applied, the one that obtained the best percentage in the information measurement process was $\mathrm{K}$ Nearest Neighbors, exceeding by $3 \%$ on average compared to all variables, in addition to using fewer variables for its process of proximity to neighbors, which were 12, compared to Naive Bayes that used 14 according to the selection process of the best parameters to analyze.

\section{CONCLUSIONS}


The analysis carried out on the examinations of the Saber Pro tests together with the student's history through supervised algorithms, allowed to highlight the trends that stand out most in the economic and social field, since this affects, both positively and negatively the student, as well as it is the residential area because in the cities there is still a greater concentration of universities and places to study professional careers.

In each analysis of the algorithms, directly proportional results were obtained between the variables and the mathematics, reading, and written communication grades, where the most significant variables were determined against the unification of the data to find patterns that may affect the performance of a student in Icfes tests.

The development of the analysis presented information biases, which altered the accuracy of results on certain variables, generating a rework of cleaning or elimination of columns that were not necessary. During each semester, the data have presented this type of problem in consequence, an improvement in the results is to add unsupervised or semi-supervised algorithms so that null variables or columns that do not have enough information can be globalized.

It was possible to determine that the regression and Bayesian algorithms were sufficiently satisfactory to obtain results above the average of the previous year by $60 \%$; combined with this, the used structure facilitated understanding, even when adding complementary functions to the algorithm as a matrix confusion or add areas such as Deep learning to strengthen the results.

\section{REFERENCES}

1. Y. Baştanlar and M. Ozuysal, Introduction to Machine Learning Second Edition, vol. 1107. 2014.

2. F. Barrera-osorio and H. B. Rodríguez, "El efecto causal de la asistencia a la universidad sobre la trayectoria educativa y el mercado laboral: Evidencia empírica para Colombia," Uniandes, vol. 1, p. 40, 2015.

3. R. Comptom and S. T. F. Studios, New School Films / True South, "El fenómeno de Finlandia. El sistema escolar más asombroso del mundo," vol. 1, 2011.

4. E. Delahoz-Dominguez, R. Zuluaga, and T. Fontalvo-Herrera, "Dataset of academic performance evolution for engineering students," Data Br., vol. 30, 2020.

5. D. E. R. Ospina, "Class relations in the higher educational system and its effects in academic performance: The case of Bogotá," Multidiscip. J. Educ. Research, vol. 9, no. 1, pp. 1-24, 2019.

6. A. Mucherino, P. J. Papajorgji, and P. M. Pardalos, “Data Mining in Agriculture (Chapter 7 Biclustering),” Optimization, vol. $34,2009$.

7. M. A. Burhanuddin, R. Ismail, N. Izzaimah, A. A.-J. Mohammed, and N. Zainol, "Analysis of Mobile Service Providers Performance Using Naive Bayes Data Mining Technique, ”Int. J. Electr. Comput. Eng., vol. 8, no. 6, p. 5153, 2018.

8. G. I. Webb, E. Keogh, R. Miikkulainen, R. Miikkulainen, and M. Sebag, “Naïve Bayes,” Encycl. Mach. Learn., pp. 713-714, 2011.

9. H. C. Kim, J. H. Park, D. W. Kim, and J. Lee, “Multilabel naïve Bayes classification considering label dependence,” Pattern Recognit. Lett., vol. 136, pp. 279-285, 2020.

10. C. C. Gray and D. Perkins, "Utilizing early engagement and machine learning to predict student outcomes," Comput. Educ., vol. 131, no. July 2018, pp. 22-32, 2019.

11. C. Masci, G. Johnes, and T. Agasisti, "Student and school performance across countries : A machine learning approach,” Eur. J. Oper. Res., vol. 269, no. 3, pp. 1072-1085, 2018. 